American Journal of Environmental Sciences 1 (4): 259-263, 2005

ISSN $1553-345 \mathrm{X}$

(C) 2005 Science Publications

\title{
Hospital Wastewater Treatment Using an Integrated Anaerobic Aerobic Fixed Film Bioreactor
}

\author{
${ }^{1}$ A. Rezaee, ${ }^{1}$ M. Ansari, ${ }^{1}$ A. Khavanin , ${ }^{1}$ A. Sabzali and ${ }^{2}$ M.M. Aryan \\ ${ }^{1}$ Department of Environmental Health, Faculty of Medical Sciences \\ Tarbiat Modares University, Tehran, Iran \\ ${ }^{2}$ Sevom Shaban Hospital, Qiyam Square, Tehran, Iran
}

\begin{abstract}
The design and operation of wastewater treatment systems for hospital is a challenge for wastewater engineers. In this study, a pilot-scale system integrated anaerobic-aerobic fixed film reactor for hospital wastewater treatment was constructed and its performance was evaluated. The aim of the study was the elimination of organic compounds and a significant reduction of bacteria. The system had been operated for 90 days. The results show that the system efficiently removed $95.1 \%$ of the chemical oxygen demand (COD) from a hospital wastewater with the influent COD of $700 \mathrm{mg} \mathrm{L}^{-1}$, leaving $34 \mathrm{mg} \mathrm{L}^{-1}$. COD in the effluent. The significant removal of pathogenic bacterial has been do after operating of the system. The advantages of the treatment system studied for small wastewater flows include: (I) simple operation and maintenance; (II) efficient removal of COD and bacteria; and (III) low-energy consumption.
\end{abstract}

Key words: Hospital, wastewater, treatment, fixed film

\section{INTRODUCTION}

Hospitals generate on average $750 \mathrm{~L}$ of wastewater by bed and a day ${ }^{[1]}$. These effluents are loaded with pathogenic microorganisms, pharmaceutical partially metabolised, radioactive elements and other toxic chemical substances. The dosage of pollutants of hospital origin shows that certain substances, such as anti-tumor agents, antibiotics and organohalogen compounds, leave mostly wastewater treatment plants $^{[2,3]}$. By leaving the wastewater treatment plants, these chemical compounds can provoke the pollution of the natural environment by entailing a biological imbalance. In case the environmental conditions allowing the degradation of these substances are not gathered, they can exercise negative effects on the receiving waters and the living species. In countries that do not experience epidemics of enteric disease and that are not endemic for intestinal helminthiasis, it is acceptable to discharge the sewage of health-care establishments to municipal sewers without pretreatment, provided that the following requirements are need: (I) the municipal sewers are connected to efficiently operated sewage treatment plants that ensure at least $95 \%$ removal of bacteria; (II) the sludge resulting from sewage treatment is subjected to anaerobic digestion, leaving no more than one helminthes egg per litre in the digested sludge; (III) the waste management system of the health-care establishment maintains high standards, ensuring the absence of significant quantities of toxic chemicals, pharmaceuticals, radionuclides, cytotoxic drugs and antibiotics in the discharged sewage; (IV) excreta from patients being treated with cytotoxic drugs may be collected separately and adequately treated ${ }^{[2,3]}$. In normal circumstances, the usual secondary bacteriological treatment of sewage, properly applied, complemented by anaerobic digestion of sludge, can be considered as sufficient. During outbreaks of enteric disease, however, or during critical periods (usually in summer time because of warm weather and in autumn because of reduced river water flow), effluent disinfection by chlorine dioxide $\left(\mathrm{ClO}_{2}\right)$ or by any other efficient process is recommended. If the final effluent is discharged into coastal waters close to shellfish habitats, disinfection of the effluent will be required throughout the year. To stop the phenomenon of excess load in the process of the wastewater treatment plant, it seems important to consider upstream treatments to hospital wastewater before their discharge in the municipal sewage system ${ }^{[4]}$. Conventional suspendedgrowth activated sludge processes, which have been used successfully and widely to treat municipal wastewater during the last hundred years, are not always suitable for treating some wastewater flows ${ }^{[5]}$. Factors that should be taken into account when designing hospital wastewater treatment plants include land requirement, construction cost, operation cost, maintenance and landscape. The plants should be operated without the continuous supervision of highlyqualified operators and should only need to be checked a few times a year. The maintenance on the mechanical parts should be easy. Biological treatment systems are used, sludge disposal should be infrequent-once or

Corresponding Author: A. Rezaee, Department of Environmental Health, Faculty of Medical Sciences Faculty, Tarbiat Modares University, Tehran, Iran 
twice per annum. Finally, the designer should make sure that the plant or facilities are in keeping with the surroundings. Therefore, the facilities for small wastewater treatment ought to be not only environmentally sound but also human friendly. There are great variety of systems that combine suspended growth processes and attached growth processes ${ }^{[6]}$. Among the latter several random media filters have been tested. Some experiences have been developed combining anaerobic and aerobic zones in separate zones in the so-called baffled reactors and employing an air-lift system for recirculation. There is considerably less experience with integrated systems allowing the co-existence of anaerobic and aerobic populations inside the same reactor without physical separation. In the system, attached-growth microorganisms in a biofilm on the surface of plastic biomedia modules, which were vertically moved repeatedly into and out of the bulk fluid, were employed to remove pollutants from wastewater, in terms of chemical oxygen demand. The fixed film system has been proven to remove nutrients efficiently from wastewater ${ }^{[7,8]}$. This study aims at presenting both the primary results on the biological characterisation of the hospital wastewater before their discharge in the municipal sewage system and their effects on the urban wastewater systems and the environment. The fixedfilm reactors with arranged media allow a simple division in anaerobic, aerobic and transition (anoxic) zones ${ }^{[9]}$. On the other hand and considering the high suspended solid concentration of wastewaters like the ones in the slaughterhouse, this packing material minimizes the clogging risk, frequent in randomsupport filters ${ }^{[10]}$. The purpose of this paper was to summarize the long-term performance experience of integrated anaerobic-aerobic fixed film bioreactor system for hospital wastewater treatment. The removal efficiency of pollutants and significant removal of pathogenic bacterial were analyzed.

\section{MATERIAL AND METHODS}

Collection of samples: Sterile $500 \mathrm{~mL}$ glass bottles were used to collect effluent sample from each stage of treatment like anaerobic, aeration and other tanks. Samples were collected twice a day (10a.m. and 2p.m.) during the study period. Duplicate samples were collected and stored in a refrigerator. After collection all the samples were processed.

The pilot-scale system: The pilot-scale system was designed and installed in Tarbiat Modaress University with a treatment capacity of $40 \mathrm{~L} /$ day of Shevom Shaban hospital wastewater. The bioreactor was separated into three equal parts by a plate. The operational phase of the unit is given in Table 1 and was controlled by electric timers.
The unit includes; aneronic, fixed film and suspended growth units. The anaerobic reactor tank was covered using strong fiberglass $15 \mathrm{~mm}$ thick shuttering. Aeration pipes were placed under the fixed film bioreactor to provide the oxygen for microorganisms and to create a mixed wastewater. The size of each biofilm media block was $0.3 \mathrm{~m} \times 0.3 \mathrm{~m}$ providing a total media surface area in the tank. A single-phase kilowatt hour meter was fitted to the electricity supply to measure the power consumption by the motor. The hospital wastewater was transfer into bioreactor and treated to evaluate the system's performance. A pump was connected to the reactor tank through a motorized valve with a $3 \mathrm{~mm}$. diameter pipe and act as the feed pipe to the reactor. A water level sensor was used to control the influent pump and to keep the water level in the bioreactor constant. An electric timer was fitted to this valve. When the timer was switched on, the reactor tank was fed with synthetic wastewater. The outlet was at a height of $0.8 \mathrm{~m}$ in the tank and was controlled by an electric timer. When the wastewater had settled after treatment the treated clarified water was allowed to flow to a pump sump.

\begin{tabular}{lll} 
Table 1: & $\begin{array}{l}\text { Operating for integrated anaerobic-aerobic fixed film } \\
\text { bioreactor }\end{array}$ \\
\hline Phase & Operation & Duration \\
\hline Anaerobic & Insert of wastewater in anaerobic tank & $6 \mathrm{~h}$ \\
Aerobic & Aeration with diffuser & $6 \mathrm{~h}$ \\
Settling & Settling of sludge & $2 \mathrm{~h}$ \\
\hline
\end{tabular}

Operation of the unit: Two cycles per day was chosen and the phases used in the bioreactor. The pump pumped the hospital wastewater into the reactor tank to give an inflow of $40_{\mathrm{L}}$ per cycle. The system was operated for 3 months. In order to simplify sludge disposal, the reactor was de-sludged once on the 30th day.

Analytical methods: COD, BOD, turbidity, $\mathrm{pH}$ and temperature were measured in accordance with the standard methods ${ }^{[11]}$. Filtered samples were obtained by filtering the wastewater through a Whatman filter paper (pore size $1.2 \mathrm{~mm}$ ). Dissolved oxygen (DO) was measured in situ with an electrochemical a digital DO meter.

Bacterial counts in liquid wastewater: All the samples were vigorously shaken before preparation of dilutions. Serial tenfold dilutions of the different treatment stage samples were prepared in diluent. All the dilutions were made in Phosphate buffered saline (NaCl-8 gm L ${ }^{-1}$, K2HPO4-1.21 gm L L $^{-1}$, KH2PO4-0.34 $\mathrm{gm} \mathrm{L}^{-1}$. with $\mathrm{pH} 7.3$ ) containing $0.05 \%$ Tween 20 . wastewater was crushed in sterile mortar and suspended in $100 \mathrm{~mL}$ diluent. Ten fold dilutions $(100 \mathrm{~mL})$ of samples were plated on nutrient agar plates in duplicate. Also, most probable number ( MPN) tests were do for bacterial counts. 
Selective bacterial counts: Tenfold dilutions $(100 \mathrm{~mL})$ of samples were plated on Mackonkey agar plates in duplicate for coliform and fecal enterococcal counts. Mackonkey agar was selected since it allows differential growth of both coliforms and enterococci.

\section{RESULTS AND DISCUSSION}

In hospital a variety of substances besides pharmaceuticals are in use for medical purposes as diagnostics and disinfectants. Besides the active substances, formulation adjuvants and in some instances, pigments and dyes are also drug components. Disinfectants, in particular are often highly complex products or mixtures of active substances. After application, many drugs are excreted non-metabolised by the patients and enter into wastewater. After their use and disinfectants also reach the wastewater. The different substances, which are not biodegradable, may finally enter surface water by wastewater treatment plants effluents and enter groundwater after the application of sewage sludge as fertilisers. The composition of the wastewater from Sevom Shaban hospital is presented in Table 1. Hospitals consume an important volume of water a day. In Sevom shaban hospital, the average needs in water was estimated at $1000 \mathrm{~L} / \mathrm{bed} /$ day $^{[12]}$. Indeed the consumption of domestic water, is on average $100 \mathrm{~L} /$ person/day, while the value generally admitted for hospitals varies from 400 to $1200 \mathrm{~L} /$ day/bed. In France, the average needs in water of a university hospital center is estimated at 750 $\mathrm{L} /$ bed/day ${ }^{[1]}$. This important consumption in water of hospitals gives significant volumes of wastewater loaded with microorganisms, heavy metals, toxic chemicals and radioactive elements ${ }^{[4]}$. As a result the hospitals generate hybrid wastewater, at the same moment domestic, industrial and effluents of care and medical research. Efficient treatment of hospital sewage should include the following operations: (I) Primary treatment, (II) Secondary biological purification; Most helminths will settle in the sludge resulting from secondary purification, together with $90-95 \%$ of bacteria and a significant percentage of viruses; the secondary effluent will thus be almost free of helminths, but will still include infective concentrations of bacteria and viruses, (III) Tertiary treatment; The secondary effluent will probably contain at least $20 \mathrm{mg}$ $\mathrm{L}^{-1}$. suspended organic matter, which is too high for efficient chlorine disinfection. It should therefore be subjected to a tertiary treatment, such as lagooning; if no space is available for creating a lagoon, rapid sand filtration may be substituted to produce a tertiary effluent with a much reduced content of suspended organic matter $\left(<10 \quad \mathrm{mg} \quad \mathrm{L}^{-1}\right)$, (IV) Chlorine disinfection; To achieve pathogen concentrations comparable to those found in natural waters, the tertiary effluent will be subjected to chlorine disinfection to the breakpoint. This may be done with chlorine dioxide (which is the most efficient), sodium hypochlorite, or chlorine gas. Another option is ultraviolet light disinfection. Disinfection of the effluents is particularly important if they are discharged into coastal waters close to shellfish habitats, especially if local people are in the habit of eating raw shellfish. The sludge from the sewage treatment plant requires anaerobic digestion to ensure thermal elimination of most pathogens. Alternatively, it may be dried in natural drying beds and then incinerated together with solid infectious healthcare waste. On-site treatment of hospital sewage will produce a sludge that contains high concentrations of helminths and other pathogens. According to the relevant WHO guidelines, the treated wastewater should contain no more than one helminthes egg per litre and no more than 1000 faecal coliforms per $100 \mathrm{~mL}$ if it is to be used for unrestricted irrigation. The sludge should be applied to fields in trenches and then covered with soil. Integrated anaerobic-aerobic fixed-film reactor with arranged media, fed with hospital wastewater, achieved organic matter removal efficiencies of $95.1 \%$. These results were consistent with the conclusions obtained by other working with integrated anaerobic/aerobic bioreactor, who pointed out that the main function of the non-aerated zone was the conversion of slowly biodegradable matter into short chain fatty acids, easily oxidized in the anoxic and aerobic processes. Anyway, it is possible that the anaerobic COD removal was underestimated because a part of methane was probably stripped in the aerobic zone. Organic matter concentration in the effluent was approximately constant, around $450 \mathrm{mg} \mathrm{L}^{-1} . \mathrm{COD}$ and $270 \mathrm{mg} \mathrm{L} \mathrm{L}^{-1}$ BOD5, independent from feed concentration and organic loading rate. Consequently, it can be considering that organic matter removal takes place simultaneously by aerobic oxidation, anoxic and anaerobic processes. It was found out that most of the COD was removed through aerobic oxidation (85\%), while the anaerobic removal stood only for $15 \%$. These results were consistent with the conclusions obtained by other working with integrated anaerobic-aerobic bioreactor, who pointed out that the main function of the non-aerated zone was the conversion of slowly biodegradable matter into short chain fatty acids, easily oxidized in the anoxic and aerobic processes. Anyway, it is possible that the anaerobic COD removal was underestimated because a part of methane was probably stripped in the aerobic zone. The main reason for the low extension of the anaerobic process was the high mixing pattern existing in the integrated reactor, which justified that the in situ measure of dissolved oxygen concentration in the samples taken from the bottom of the anaerobic zone were dissolved oxygen, which seriously limited the anaerobic process. In fact, the biomass accumulated at the bottom of the aerated zone did not present any nitrifying activity, according to the respirometry tests. 
Am. J. Environ. Sci., 1 (4): 259-263, 2005

Table1: Feed and effluent wastewater characteristics

\begin{tabular}{lllllllcl}
\hline & COD & $\begin{array}{l}\text { BOD5 } \\
\left(\mathrm{mg} \mathrm{L}^{-1}\right)\end{array}$ & $\begin{array}{l}\text { NH4+-N } \\
\left(\mathrm{mg} \mathrm{L}^{-1}\right)\end{array}$ & $\begin{array}{l}\text { Turbidity } \\
(\mathrm{NTU})\end{array}$ & $T(\mathrm{C})$ & $\mathrm{pH}$ & $\begin{array}{c}\text { Coliforms } \\
(\text { number/100 mL) }\end{array}$ & $\begin{array}{l}E . \text { coli } \\
(\text { number/100 mL) }\end{array}$ \\
\hline Influent & 450 & 270 & 18 & 95 & 24 & $6-8$ & $4 \times 103$ & $>1600$ \\
Effluent & 80 & 30 & 2.5 & $<5$ & 24 & 7.2 & 400 & $<30$ \\
\hline
\end{tabular}

Competition for dissolved oxygen inside the biofilm will depend strongly on the biofilm thickness and the distribution of heterotrophic and autotrophic populations. Biofilm showed an autotrophicheterotrophic activity accumulation. The hospital effluents have generally a very weak microbiological load resulting from the regular use of disinfectants. These bactericides can have a negative influence on the biological processes of the wastewater treatment plant. Even by considering that these effluents are diluted after their discharge towards the municipal wastewater treatment plant, it remains evident that it is not necessary to neglect the possibility that certain substances present in the wastewater treatment plant effluents can generate by cumulative effect a biological imbalance in aquatic ecosystem. To protect the natural environment against the phenomenon of excess load in the processes of the wastewater treatment plant, it seems important to consider upstream treatments of hospital wastewater before their discharge in the municipal sewage system ${ }^{[13]}$. Indeed, the contact of hospital pollutants with the elements of the aquatic ecosystems puts in evidence a danger which is bound to the existence of hazardous substances, i.e., which have the potentiality to exercise negative effects on the environment and the living species ${ }^{[14]}$. In case the environmental conditions allowing the degradation of these substances are not gathered, hospital pollutants risk to be present for a long time in the natural environment and can represent a risk in short, middle and long term for the living species of the ecosystems. The risk is the probability of appearance of toxic effects after the exposure of the living organisms to hazardous objects. The existence of a possible exposure of biological, chemical and radioactive substances released by hospital effluents conducts to take into account, the eventuality of a radioactive chemical and microbiological risk for the abiotic system and the living species which populate them. The characterisation works realized on the microbiology of the hospital effluents put in evidence in a systematic way the presence of germs having acquired the characters of resistance in antibiotics ${ }^{[2]}$. Concentrations of bacteria flora from $2,4 \times 103 / 100 \mathrm{~mL}$ to $3 \times 105 / 100 \mathrm{~mL}$ are deducted for the hospital effluents. These concentrations are lower than that of the $108 / 100 \mathrm{~mL}$ generally present in the municipal sewage system was deducted for the hospital wastewater ${ }^{[14,15]}$. Markers of viral pollution of surface water, such as enterovirus and other viruses such adenovirus, were identified in the hospital effluents. Enterovirus appears in important quantity in wastewater. Their presence, as marker of viral pollution, in the hospital effluents is to correlate to that of other viruses. Besides, the HIV, causal agent of the AIDS, was isolated from biological liquids and excretions of infected persons. These liquid effluents, directly rejected in the network drainage of research laboratories and hospitals, can contribute under certain physico-chemical conditions to the presence of the virus in the urban sewer networks and in the wastewater treatment plant). Hospital wastewater reveals the presence of molecules chlorinated in high concentrations and in a punctual way the presence of heavy metals such as mercury and silver. Wastewater composition refers to the actual amounts of physical, chemical and biological constituents present in wastewater. Depending on the concentration of these constituents, municipal wastewaters are classified in strong, medium or weak ${ }^{[9]}$. On the basis of this information, Chitnis have compared the average concentrations obtained for the hospital effluents with the medium values of the municipal wastewater ${ }^{[3]}$. This comparison allows appreciating the strong content in pollutants of the hospitable effluents.

\section{REFERENCES}

1. Boller, M., 1997. Small wastewater treatment plants-a challenge to wastewater engineers. Wat. Sci. Technol., 35:1-12.

2. Chitnisa, V., S. Chitnisa, K. Vaidyaa, S. Ravikanta, S. Patilb and D.S. Chitnisa, 2004. Bacterial population changes in hospital effluent treatment plant in central India. Wat. Res., 38: 441-447

3. Chitnis V., D.S. Chitnis, S. Patil and S. Ravi Kant, 2000. Hospital effluent: a source of multiple drug resistant bacteria. Curr. Sci., 79: 989-91.

4. Tsai C.T and S.T. Lin, 1999. Disinfection of hospital waste sludge using hypochlorite and chlorine dioxide. J. Appl. Microbiol., 86: 827-33.

5. Kumar, B.M. and S. Chaudhari, 2003. Evaluation of sequencing batch reactor (SBR) and sequencing batch biofilm reactor (SBBR) for biological nutrient removal from simulated wastewater containing glucose as carbon source. Wat. Sci. Technol., 48: 73-9. 
6. Tchobanoglous G, F.L. Burton and M.D. Stensel, 2003. Wastewater Engineering: Treatment and Reuse. New York: Metcalf \& Eddy.

7. Gieseke A., P. Arnz, R. Amann and A. Achramm, 2002. Simultaneous $P$ and $N$ removal in a sequencing batch biofilm reactor: in lights from reactor and microscale investigations. Wat. Res., 36: 501-9.

8. Rodgers, M., 1999. Organic carbon removal using a new biofilm reactor. Wat. Res., 33: 1495-9.

9. Rodgers, M., X.M. Zhan and B. Gallaghe, 2003. A pilot plant study using a vertically moving biofilm process to treat municipal wastewater. Bioresour. Technol., 89:139-43.

10. Morgenroth, E. and P.A. Wilderer, 1999. Controlled biomass removal-the key parameter to achieve enhanced biological phosphorus removal in biofilm systems. Wat. Sci. Technol., 39: 33-40.
11. APHA., 1995. Standard Methods for the Examination of Water and Wastewater, 19th ed. Washington: American Public Health Association.

12. EPA., 1999. Wastewater Treatment Manuals: Treatment Systems for Small Communities, Business, Leisure Centres and Hotels. Ireland.

13. Altinbas, U., 2001. Nutrient removal from low strength domestic wastewater in sequencing batch biofilm reactor. Wat. Sci. Technol., 44: 181-6.

14. Wen, X., H. Ding, X. Huang and R. Liu, 2004. Treatment of hospital wastewater using a submerged membrane bioreactor. Process Biochem., 39: 1427-1431.

15. Tsai, C.T., J.S. Lai and S.T. Lin, 1998. Quanti.cation of pathogenic microorganisms in the sludge from treated hospital wastewater. J. Appl. Microbiol., 85: 171-6. 